УДК $621.181 .27: 621.182 .4$

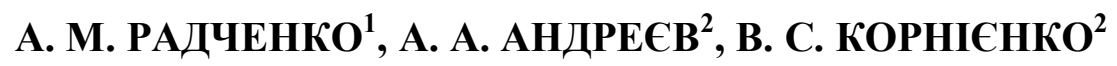

${ }^{1}$ Національний університет кораблебудування ім. адм. Макарова, Миколаӥв, Украйна

${ }^{2}$ Херсонська філія Національного університету кораблебудування ім. адм. Макарова, Украӥна

\title{
ЗАБРУДНЕННЯ ПОВЕРХОНЬ НАГРІВУ УТИЛІЗАЦІЙНИХ КОТЛІВ ПРИ СПАЛЮВАННІ ВОДОПАЛИВНИХ ЕМУЛЬСІЙ НА ОСНОВІ МАЛОВ'ЯЗКИХ ПАЛИВ
}

\begin{abstract}
На основі проведених експериментальних і теоретичних досліджень отримано залежності питомого збільшення маси забруднення від коефіцієнта надлишку повітря при різному водовмісті водопаливної емульсії на основі малов'язких палив. Проведено статистичну обробку результатів досліджень, яка показала переважний вплив на питоме збільшення маси забруднення вмісту сірки і води в водопаливній емульсії, а потім коефіиієнта надлишку повітря. Розроблено тривимірну модель і рівняння регресії, щзо враховують вплив на величину питомого збільшення маси забруднення основних параметрів. Отримано контурні графіки залежностей питомого збільшення маси забруднення від вмісту сірки, води в водопаливній емульсії і коефіцієнту надлишку повітря.
\end{abstract}

Ключові слова: утилізачійний котел, конденсаційна поверхня нагріву, забруднення, водопаливна емульсія, малов'язке паливо.

\section{Вступ}

При спалюванні сірчистих палив внаслідок інтенсивної низькотемпературної сірчанокислотної корозії (НТК) (більше 1 мм/рік) при температурах

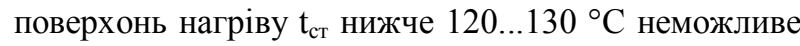
використання конденсаційних низькотемпературних поверхонь нагріву (НТПН) і відповідно теплоти конденсації водяної пари і сірчаної кислоти. При спалюванні водопаливних емульсій (ВПЕ) 3 водовмістом $\mathrm{W}^{\mathrm{r}}=30 \%$ спостерігається [1] істотне зниження інтенсивності НТК до рівня 0,25 мм/рік, завдяки пасивації металу під тонким шаром конденсату сірчаної кислоти абсорбованими оксидами азоту [2], що надає можливість встановлення конденсаційних НТПН при температурі стінки $\mathrm{t}_{\text {ст }}$ нижче температури точки роси парів сірчаної кислоти $\mathrm{t}_{\mathrm{pH}_{2} \mathrm{SO}_{4}} \mathrm{i}$, отже, забезпечує можливість використання теплоти конденсації парів $\mathrm{H}_{2} \mathrm{O}$ i $\mathrm{H}_{2} \mathrm{SO}_{4}$ при $\mathrm{t}_{\text {ст }}$ аж до $65 \ldots 75^{\circ} \mathrm{C}$ при високій надійності роботи цих конденсаційних НТПН. При проходженні в шарі конденсату і забруднень процесів за нітрозним механізмом в шарі забруднень з'являються внутрішні джерела теплоти, так як виділяється теплота абсорбції $\mathrm{NO}_{\mathrm{x}}$ i $\mathrm{SO}_{2}$, утворення додаткової кількості $\mathrm{H}_{2} \mathrm{SO}_{4}$, розбавлення кислоти, реакцій утворення нітрозілсірчаної кислоти, що збільшує значення теплового потоку в конденсаційних НТПН утилізаційних котлів (УК).
При цьому одночасно зростає інтенсивність забруднення НТПН, внаслідок чого знижується інтенсивність теплопередачі в поверхнях нагріву, зростає аеродинамічний опір УК. Досвід експлуатації котельних установок свідчить про те, що боротьба 3 низькотемпературними забрудненнями (НT3) є завданням не менш актуальним, ніж захист поверхонь нагріву від НТК. При спалюванні сірчистих ВПЕ спостерігається зниження інтенсивності НТ3 [3], що пояснюється значним поліпшенням якості процесу горіння в наслідок мікровибухів крапель ВПЕ і збільшення поверхні контакту парів палива 3 окиснювачем. Зі збільшенням коефіцієнта надлишку повітря $\alpha$ при спалюванні стандартних рідких палив в вихлопних газах ДВЗ зменшується вміст твердих часток, що призводить до зниження їх димності [4].

В [5] наведено результати експериментальних досліджень впливу спалювання стандартного дизельного палива (ДП) і палива екологічного дизельного (ПЕД) з вмістом води $12,3 \% ; 19,4 \% ; 23,2 \% ; 31,2 \%$ по масі на показники токсичності та димності відпрацьованих газів.

На думку авторів [5] безперечною перевагою використання ПЕД в дизелі є їі вплив на димність відпрацьованих газів, яка на режимах максимального навантаження зменшилась в $1,3 \ldots 1,4$ рази при використанні ПЕД-19,4 і в 1,3...2,7 рази при використанні ПЕД-31,2. Витрата чистого палива в ПЕД при збільшенні вмісту води зменшується до $\sim 6 \%$, хоча 
загальна витрата ПЕД збільшується. Найбільш ефективним 3 точки зору економії палива є використання ПЕД з вмістом води $15 \ldots 25 \%$.

За даними $[5,6]$ застосування ПЕД не вимагає конструктивних переробок дизеля і дозволяє помітно поліпшити екологічні характеристики ДВЗ.

\section{Постановка задачі}

Мета роботи - отримання залежностей питомого збільшення маси забруднення $\Delta \mathrm{G}_{3}$ при впливі: коефіцієнта надлишку повітря $\alpha$ (до 2,5 ... 2,9), вмісту сірки $\mathrm{S}^{\mathrm{r}}(1 \ldots 2 \%)$ і водовмісту $\mathrm{W}^{\mathrm{r}}(2 \ldots 30 \%)$ при спалюванні малов'язких палив і ВПЕ на їх основі.

\section{Результати досліджень}

На основі проведених експериментальних і теоретичних досліджень при спалюванні малов'язких палив $\quad$ (ДЛ+ДТ) $\left(\alpha=2,9, \quad \mathrm{~S}^{\mathrm{r}}=1,5 \%, \mathrm{~W}^{\mathrm{r}}=2 \%\right.$, зольність $0,01 \%)[1,3,7]$ з урахуванням даних $[8,9]$ були отримані залежності питомого збільшення маси забруднення $\Delta \mathrm{G}_{3}$ від коефіцієнта надлишку повітря $\alpha$ при різному водовмісті ВПЕ.

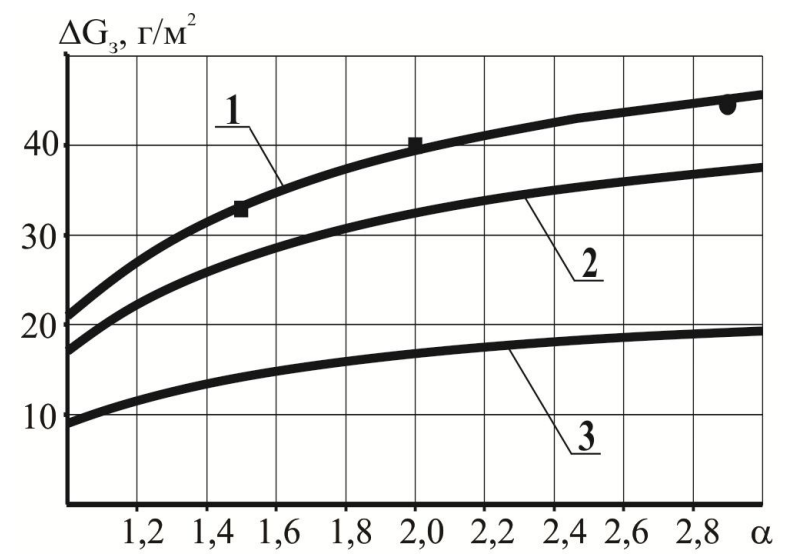

Рис. 1. Залежність $\Delta \mathrm{G}_{3}$ в області кислотного піка $\left(\mathrm{t}_{\mathrm{cт}}=110{ }^{\circ} \mathrm{C}\right)$ від $\alpha$ при різному водовмісті $\mathrm{W}^{\mathrm{r}} \mathrm{BПЕ}$ на основі малов'язких палив при $\mathrm{S}^{\mathrm{r}}=1,5 \%$

$$
\text { ( } \tau=8 \text { год): }
$$

$1-\mathrm{W}^{\mathrm{r}}=2 \% ; 2-\mathrm{W}^{\mathrm{r}}=17 \% ; 3-\mathrm{W}^{\mathrm{r}}=30 \%$

Для оцінки спільного впливу розглянутих 3-х факторів $\left(\alpha, \mathrm{S}^{\mathrm{r}}, \mathrm{W}^{\mathrm{r}}\right)$ на інтенсивність забруднення $\Delta \mathrm{G}_{3}$, визначення значень констант і вагових коефіцієнтів в рівнянні багатофакторної регресії, визначення факторів істотного впливу на $\Delta \mathrm{G}_{3}$ була використана система Statgraphics Plus for Windows, яка забезпечує доступ до повного набору статистичних методів і надає можливість провести розширений регресійний аналіз.

Статистична обробка даних дозволила отримати при спалюванні малов'язких палив і ВПЕ на їх основі рівняння, що враховує вплив на величину питомого збільшення маси забруднення $\Delta \mathrm{G}_{3}$ коефіцієнта надлишку повітря $\alpha$, вмісту сірки $\mathrm{S}^{\mathrm{r}}$ в паливі та води $\mathrm{W}^{\mathrm{r}}$ у ВПЕ у вигляді:

$$
\begin{aligned}
& \Delta \mathrm{G}_{3}=-48,9368+4,5106 \alpha+56,6757 \mathrm{~S}^{\mathrm{r}}+1,7755 \mathrm{~W}^{\mathrm{r}}- \\
& -1,0343 \alpha^{2}+7,2389 \alpha \mathrm{S}^{\mathrm{r}}-0,1375 \alpha \mathrm{W}^{\mathrm{r}}- \\
& -11,0309\left(\mathrm{~S}^{\mathrm{r}}\right)^{2}-0,9136 \mathrm{~W}^{\mathrm{r}} \mathrm{S}^{\mathrm{r}}-0,027\left(\mathrm{~W}^{\mathrm{r}}\right)^{2}
\end{aligned}
$$

Рівняння дає прийнятні значення $\Delta \mathrm{G}_{3}$ в діапазоні значень $\alpha=1,5 \ldots 2,9, \mathrm{~S}^{\mathrm{r}}=0,98 \ldots 2 \% \mathrm{i} \mathrm{W}^{\mathrm{r}}=2 \ldots 30 \%$.

На рис. 2 представлена тривимірна модель залежності $\Delta \mathrm{G}_{3}=\mathrm{f}\left(\mathrm{S}^{\mathrm{r}}, \mathrm{W}^{\mathrm{r}}\right)$ при значеннях $\alpha=2,9$.

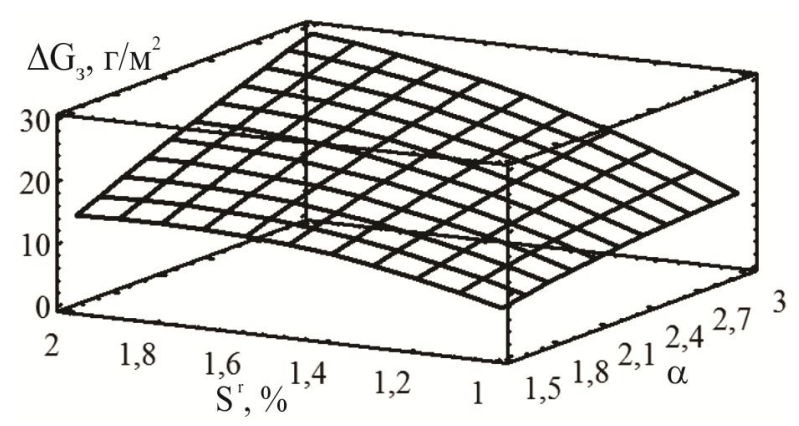

Рис. 2. Тривимірна модель залежності $\Delta \mathrm{G}_{3}=\mathrm{f}\left(\mathrm{S}^{\mathrm{r}}, \alpha\right)$ при значенні $\mathrm{W}^{\mathrm{r}}=30 \%$

Представлена на рис. 3 карта Парето вказує на те, що на величину $\Delta \mathrm{G}_{3}$ перш за все впливає вміст сірки $\mathrm{S}^{\mathrm{r}}$, водовміст $\mathrm{W}^{\mathrm{r}}$ ВПЕ і коефіцієнт надлишку повітря $\alpha$.

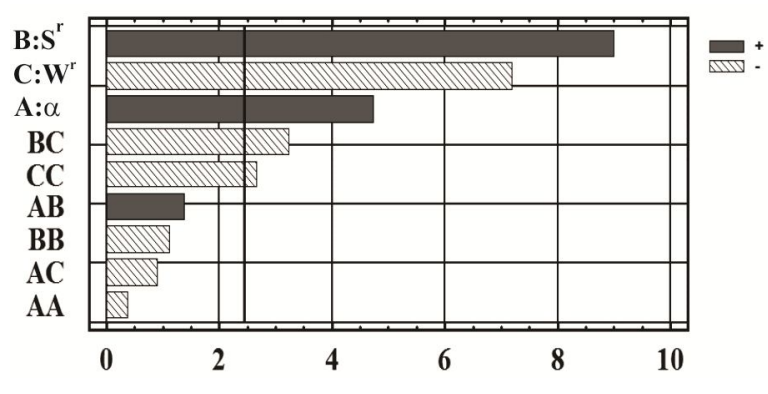

Рис. 3. Карта Парето

На рис. 4, а, б представлено контурні графіки залежностей $\Delta \mathrm{G}_{3}=\mathrm{f}\left(\mathrm{S}^{\mathrm{r}}, \mathrm{W}^{\mathrm{r}}\right)$ при значеннях $\alpha=2,9 \mathrm{i}$ $\alpha=2,0$.

На рис. 5, а, б представлено контурні графіки залежностей $\Delta \mathrm{G}_{3}=\mathrm{f}\left(\mathrm{S}^{\mathrm{r}}, \alpha\right)$ при значеннях $\mathrm{W}^{\mathrm{r}}=2 \%$, $\mathrm{W}^{\mathrm{r}}=30 \%$.

На рис. 6, а, б представлено контурні графіки залежностей $\Delta \mathrm{G}_{3}=\mathrm{f}\left(\mathrm{W}^{\mathrm{r}}, \alpha\right)$ при значеннях $\mathrm{S}^{\mathrm{r}}=2 \%$, $\mathrm{S}^{\mathrm{r}}=1,5 \%$. 

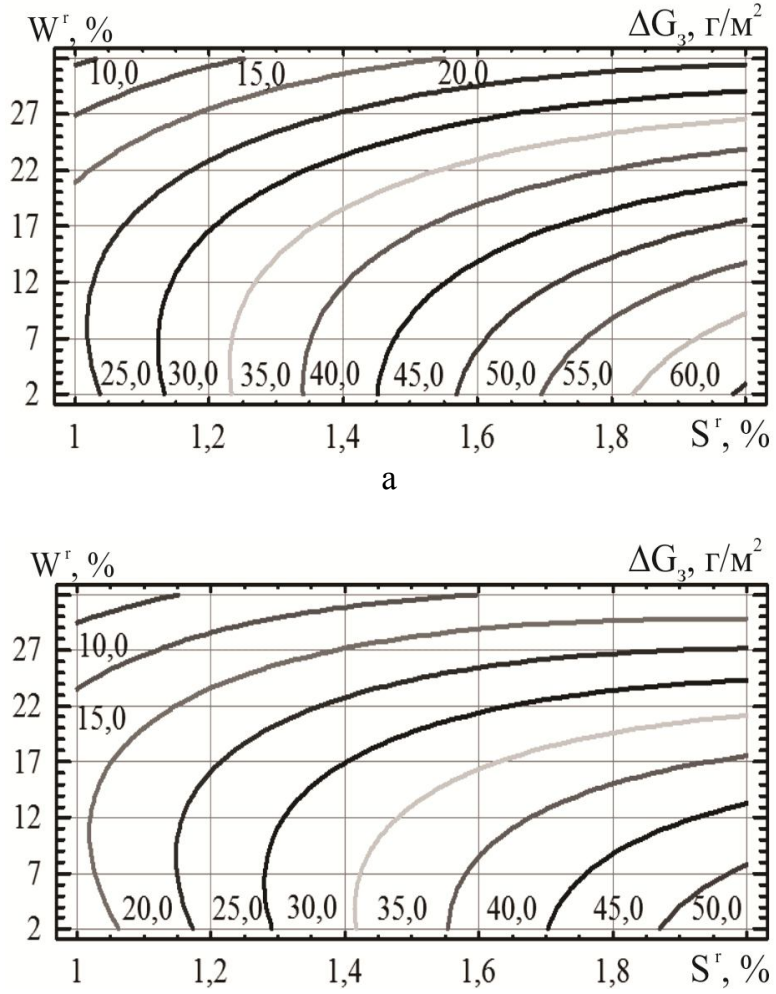

6

Рис. 4. Контурна поверхня залежностей $\Delta \mathrm{G}_{3}=\mathrm{f}\left(\mathrm{S}^{\mathrm{r}}, \mathrm{W}^{\mathrm{r}}\right)$ при: $\mathrm{a}-\alpha=2,9 ; \sigma-\alpha=2,0$
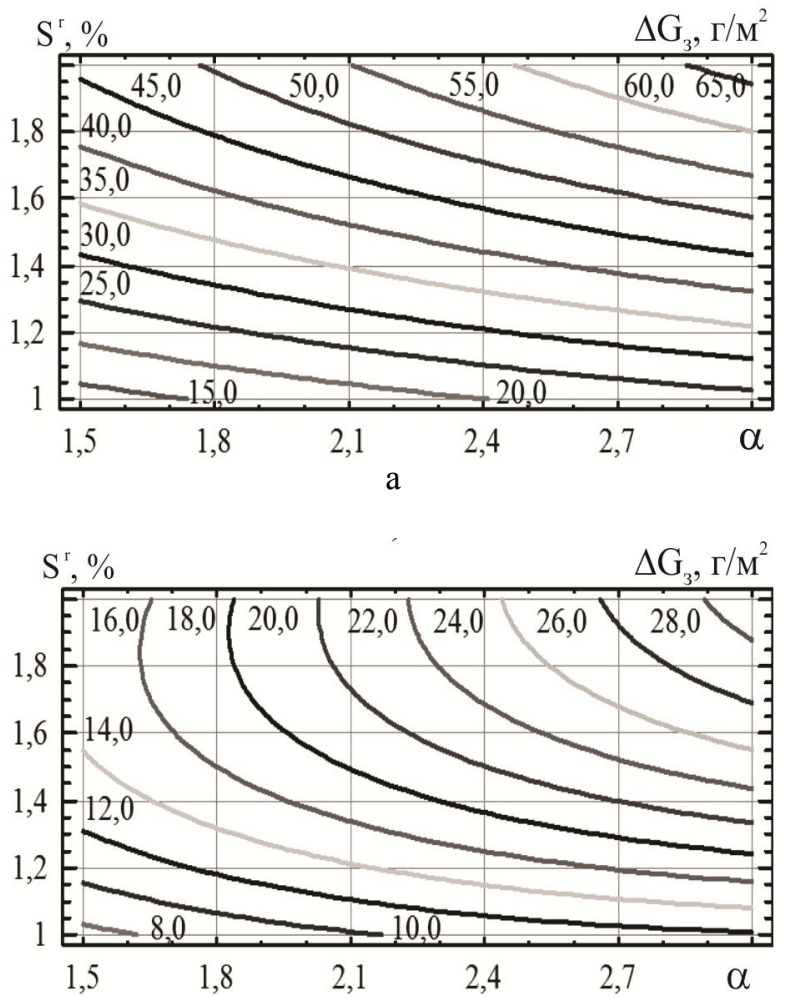

6

Рис. 5. Контурна поверхня залежностей $\Delta \mathrm{G}_{3}=\mathrm{f}\left(\mathrm{S}^{\mathrm{r}}, \alpha\right)$ при: $\mathrm{a}-\mathrm{W}^{\mathrm{r}}=2 \% ; \sigma-\mathrm{W}^{\mathrm{r}}=30 \%$
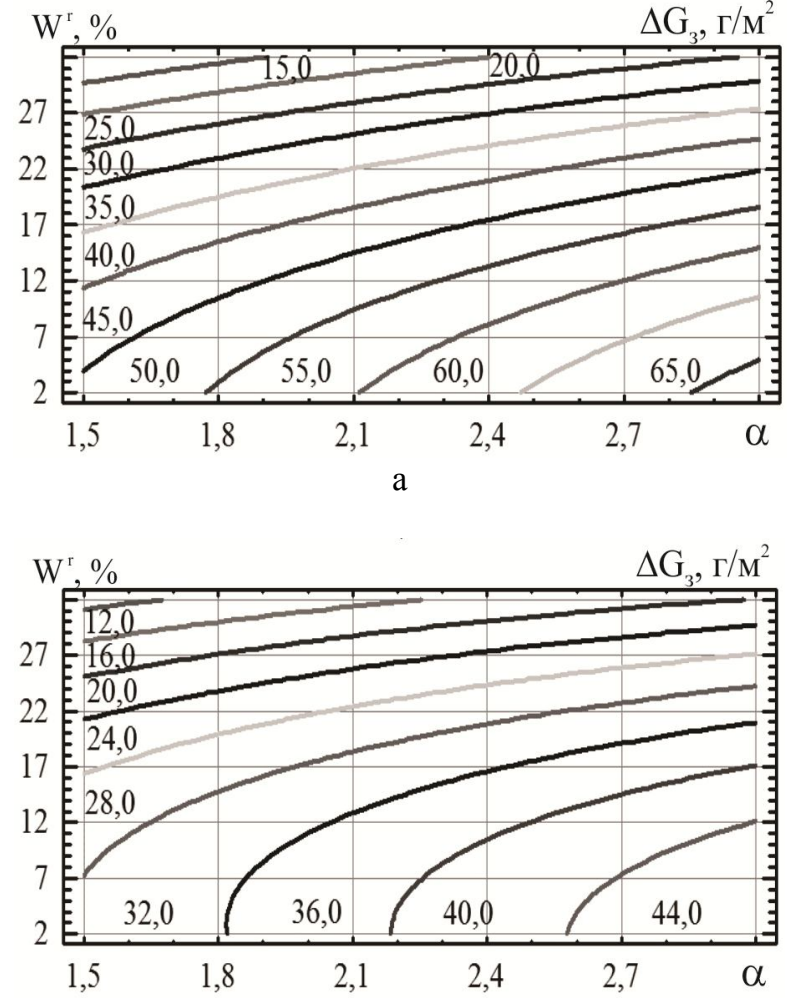

б

Рис. 6. Контурна поверхня залежностей $\Delta \mathrm{G}_{3}=\mathrm{f}\left(\mathrm{W}^{\mathrm{r}}, \alpha\right)$ при: $\mathrm{a}-\mathrm{S}^{\mathrm{r}}=2 \% ; \sigma-\mathrm{S}^{\mathrm{r}}=1,5 \%$

Представлені в роботі залежності $\Delta \mathrm{G}_{3}$ від різних факторів дозволили сформулювати наступні висновки.

\section{Висновки}

1. При спалюванні малов'язких палив при збільшенні коефіцієнта надлишку повітря 31,5 до 2,9 величина $\Delta \mathrm{G}_{3}$ зростає в 1,36 рази; при спалюванні ВПЕ з водовмістом $30 \%$ - величина $\Delta \mathrm{G}_{3}$ зростає в 1,33 рази.

2. При збільшенні водовмісту ВПЕ 32 до $30 \%$ значення $\Delta \mathrm{G}_{3}$ зменшується в 2,37 рази.

3. Отримані залежності і рівняння регресії $\Delta \mathrm{G}_{3}=\mathrm{f}\left(\alpha, \mathrm{S}^{\mathrm{r}}, \mathrm{W}^{\mathrm{r}}\right)$ можуть бути використані при проектуванні поверхонь нагріву УК.

\section{Литература}

1. Горячкин, В. Ю. Интенсивность коррозионных проиессов в утилизачионных котлах при сжигании водотопливных эмульсий [Текст] / В. Ю. Горячкин, В. С. Корниенко // Вестник Астраханского государственного технического универси- 
тета. Сер.: Морская техника и технология. 2013.- № 2. - C. 101-110.

2. Пат. 99408 Україна, МПК С23F 11/10, F22B 37/00, F23J 15/00. Спосіб захисту металу низькотемпературних поверхонь нагріву котла від сірчанокислотної корозї [Текст] / В. Ю. Горячкін, А. В. Горячкін, О.В. Акімов, В. О. Іутінський, B. С. Корніснко; заявник Національний університет кораблебудування імені адмірала Макарова. - заявл. 23.08.11; опубл. 10.08.12, Бюл. № 15.

3. Корниенко, В. С. Интенсивность процессов загрязнения поверхностей нагрева утилизачионных котлов при сжигании водомазутных эмульсий [Текст]/ В.С. Корниенко // Авиационно-космическая техника и технология. - 2017. - № 1 (136). - C. 48-53.

4. Долганов, К. Е. Методика аппроксимаџии характеристик дымности отработавших газов дизелей [Текст] / К. Е. Долганов, А. П. Поляков // Экотехнологии и ресурсосбережение - 1997. - № 2. - C. 47-50.

5. Парсаданов, И. В. Применение водотопливной эмульсии в автотракторном дизеле. Экологическая эффективность (часть 1) [Текст] / И. В. Парсаданов, И. В. Теплицкий, В. В. Солодовников // Двигатели внутреннего сгорания. - 2011. - № 2. - C. 118-120.

6. Zang, T. Experimental study on water particles in the combustion of marine four-stoke diesel engine operated with emulsified fuels [Text] / T. Zhang, H. Okada, T. Tsukamoto, K. Ohe // CIMAK 2007. Vienna, 2007. - Paper № 193.

7. Корниенко, В. С. Исследование динамики низкотемпературной коррозии и загрязнения поверхностей нагрева утилизационных котлов [Текст] / В. С. Корниенко // Рибне господарство Украӥни. - 2013. - № 3(86). - С. 62-65.

8. Низкотемпературная коррозия и загрязнение поверхностей нагрева в продуктах сгорания ГТД [Текст] / В. А. Романов, Г. И. Дмитриев, В. И. Щербинкин, Г. В. Проченко // Энергомашиностроение. - 1979. - № 8. - C. 22-25.

9. Романов, В. А. Загрязнение низкотемпературных поверхностей нагрева судового парогенератора и эффективность некоторых методов очистки [Текст] / В. А. Романов, Г. И. Дмитриев, В. И. Щербинкин // Энергомашиностроение. - 1978. - № 8. -C. 47-52.

\section{References}

1. Goryachkin, V. Yu., Kornienko, V. S. Intensivnost' korrozionnykh protsessov $\mathrm{v}$ utilizatsionnykh kotlakh pri szhiganii vodotoplivnykh emul'sii [Intensity of corrosion processes in exhaust gas boilers at burning water fuil emulsion]. Vestnik Astrahanskogo gosudarstvennogo tehnicheskogo universiteta. Serija: Morskajatehnika i tehnologija, 2013, no. 2, pp. 101-110.

2. Goryachkin, V. Yu., Goryachkin, A. V., Akimov, O. V., Iutins'kii, V. O., Kornienko, V. S. Sposib zakhistu metalu niz'kotemperaturnikh poverkhon' nagrivu kotla vid sirchanokislotnoï koroziï [Method of protection low-temperature heating surfaces of boiler of sulfuric acid corrosion]. Patent of Ukraine, no. 99408, 2012.

3. Korniyenko V. S. Intensivnost' protsessov zagriazneniia poverkhnostei nagreva utilizatsionnykh kotlov pri szhigani vodomazutnykh emul'sii [Intensivity of pollution processes in exhaust gas boilers at burning water-fuel emulsion]. Aviacijno-kosmicna tehnika $i$ tehnologia - Aerospace technic and technology, 2017, no. 1 (136), pp. 48-53.

4. Dolganov K. E., Polyakov A. P. Metodika approksimatsii kharakteristik dymnosti otrabotavshikh gazov dizelei [Method of approximation of smoke exhaust characteristics of diesel engines]. Ekotekhnologiiiresursosberezhenie,1997, no. 2, pp. 47-50.

5. Parsadanov, I. V., Solodovnikov, V. V. Primenenie vodotoplivnoi emul'sii $\mathrm{v}$ avtotraktornom dizele. Ekologicheskaya effektivnost' (chast' 1) [Application of water fuel emulsion in autotractor diesel. Ecological efficiency (part 1)]. Dvigateli vnutrennego sgoraniya, 2011, no. 2, pp. 118-120.

6. Zhang, T., Okada, H., Tsukamoto, T., Ohe, K. Experemental study on water particles in the combustion of marine four-stoke diesel engine operated with emulsified fuels. CIMAK 2007, Vienna, Paper no. 193.

7. Kornienko, V. S. Issledovanie dinamiki nizkotemperaturnoi korrozii i zagryazneniya poverkhnostei nagreva utilizatsionnykh kotlov [Research of low temperature corrosion and pollution dynamics lowtemperature heating surfaces of exhaust gas boilers]. Ribne gospodarstvo Ukraïni, 2013, no. 3(86), pp. 6265.

8. Romanov, V. A. Dmitriev, G. I., Shherbinkin, V. I., Procenko, G. V. Nizkotemperaturnaja korrozija i zagrjaznenie poverhnostej nagreva $\mathrm{V}$ produktah sgoranija GTD [Low-temperature corrosion and pollution of heating surfaces in combustion products GTE]. Jenergomashinostroenie, 1979, no. 8, pp. 22-25.

9. Romanov, V. A., Dmitriev, G. I., Shherbinkin, V. I. Zagrjaznenie nizkotemperaturnyh poverhnostej nagreva sudovogo parogeneratora i jeffektivnost' nekotoryh metodov ochistki [Pollution of low-temperature heating surfaces of the ship's steam boiler and efficiency of some cleaning methods]. Jenergomashinostroenie, 1978, no. 8, pp. 4752 . 


\section{ЗАГРЯЗНЕНИЯ ПОВЕРХНОСТЕЙ НАГРЕВА УТИЛИЗАЦИОННЫХ КОТЛОВ ПРИ СЖИГАНИИ ВОДОТОПЛИВНЫХ ЭМУЛЬСИЙ НА ОСНОВЕ МАЛОВЯЗКИХ ТОПЛИВ}

\section{А. Н. Радченко, А. А. Андреев, В. С. Корниенко}

На основе проведенных экспериментальных и теоретических исследований получены зависимости удельного увеличения массы загрязнения от коэффициента избытка воздуха при разном водосодержании водотопливной эмульсии на основе маловязких топлив. Проведена статистическая обработка результатов исследований, которая показала преобладающее влияние на удельное увеличение массы загрязнения содержания серы и воды в водотопливной эмульсии, а затем коэффициента избытка воздуха. Получена трехмерная модель и уравнения регрессии, учитывающие влияние на величину удельного увеличения массы загрязнения основных параметров. Получены контурные графики зависимостей удельного увеличения массы загрязнения от содержания серы, воды в водотопливной эмульсии и коэффициента избытка воздуха.

Ключевые слова: утилизационный котел, конденсационная поверхность нагрева, загрязнения, водотопливная эмульсия, маловязкое топливо.

\section{POLLUTION OF EXHAUST GAS BOILERS HEATING SURFACES DURING COMBUSTION OF WATER-FUEL EMULSION BASED ON LOW-VISCOSITY FUELS}

\section{A. N. Radchenko, A. A. Andreev, V. S. Kornienko}

The analysis of literature data, which showed a decrease fuel consumption and smoke emissions of diesel engines during the combustion of water-fuel emulsions based on diesel fuel, was carried out. The combustion of waterfuel emulsions decreases the intensity of low-temperature pollution, which is explained by significant improvement in the quality of the combustion process as a result of micro explosions emulsion droplets and an increase in the contact surface of fuel vapor with the oxidizer. According to the literature data, the use of water-fuel emulsion does not require constructive alterations of the diesel engine and can significantly improve the environmental characteristics of the engine. Based on the experimental and theoretical studies, the relations of the specific increase in the mass of pollution on the excess air factor for different water content of water-fuel emulsion based on low-viscosity fuels were obtained. For evaluation of the joint effect of three factors on the pollution intensity in the statistical processing of experimental data, the Statgraphics Plus for Windows system, providing access to a full set of statistical methods and providing an opportunity to conduct an extended regression analysis was used. Statistical processing of the research results, which showed the prevailing influence on the specific increase in the mass of pollution of the sulfur and water content in the water-fuel emulsion, and then the excess air factor, was carried out. A threedimensional model and regression equations that take into account the effect on the value of the specific increase in the mass of pollution of the main parameters are obtained. The contour graphs of the dependences of the specific increase in the mass of pollution on the sulfur content, water content in the water-fuel emulsion and the excess air factor are obtained. Analysis of the research results shows that burning of water-fuel emulsions based on lowviscosity fuels with water content of $30 \%$ reduces the level of pollution of heating surfaces by 2,36 times. The obtained relations can be used in the design of condensing heating surfaces.

Keywords: exhaust gas boilers, condensing heating surface, pollution, water-fuel emulsion, low-viscosity fuel.

Радченко Андрей Николаевич - канд. техн. наук, доцент, докторант, Национальный университет кораблестроения имени адмирала Макарова, Николаев, Украина, e-mail: nirad50@gmail.com.

Андреев Андрей Адольфович - канд. техн. наук, доцент, зав. кафедрой, Херсонский филиал Национального университета кораблестроения имени адмирала Макарова, Херсон, Украина, е-таil: andreev.cme@gmail.com.

Корниенко Виктория Сергеевна - преподаватель, Херсонский филиал Национального университета кораблестроения имени адмирала Макарова, Херсон, Украина, e-mail: kornienkovika1987@gmail.com.

Radchenko Andrey Nikolaevich - PhD, Associate Professor, doctorant, Admiral Makarov National University of Shipbuilding, Nikolayev, Ukraine, e-mail: nirad50@gmail.com.

Andreev Andrey Adolfovich - PhD, Associate Professor, Head of the Department, Kherson branch of Admiral Makarov National University of Shipbuilding, Kherson, Ukraine, e-mail: andreev.cme@gmail.com.

Kornienko Victoriya Sergeevna - teacher, Kherson branch of Admiral Makarov National University of Shipbuilding, Kherson, Ukraine, e-mail: kornienkovika1987@gmail.com. 